\title{
RESPONSABILIDAD DEL EMPLEADOR POR LOS ACTOS DE ACOSO LABORAL DE SUS SUBORDINADOS. COMENTARIO DEL FALLO DEL TRIBUNAL DE LETRAS del Trabajo de Temuco, 24 DE ABRIL DE 2012, RIT T-10-2012
}

\section{Pablo Arellano Ortiz*}

\section{1) INTRODUCCIÓN}

Una sentencia condenatoria de derechos fundamentales contra un Conservador de Bienes Raíces puede resultar extraño. Sobre todo luego de una discusión ya zanjada sobre si este tipo de funcionario constituyen o no empresa. Al ser considerada empresa por la legislación sus trabajadores pueden, con justo derecho, ampararse en las normas protectoras del Código del Trabajo.

De esta manera, cinco trabajadoras del Segundo Conservador de Bienes Raíces de la ciudad de Temuco, Roberto Hadi, recurren ante el tribunal respectivo interponiendo una acción de tutela por violación de sus derechos fundamentales de su empleador hacia ellas. Reiterados hechos de hostigamiento y maltrato sufrieron estas trabajadoras lo que llevó a encontrarse con licencia médica y con tratamiento psiquiátrico, según se constata de la declaración de los testigos. Además, la sentencia demuestra que de la prueba rendida se encuentra acreditado que los hechos que se le imputan a la dependiente, y cónyuge del demandado, existieron y que ellos consistieron en utilización de lenguaje grosero, tirar carpetas encima de los escritorios, menoscabos en términos personales y en la calidad del trabajo diario. Todos los hechos descritos afectaron gravemente la autoestima de las denunciantes. Este caso presenta la particularidad que el empleador, cónyuge de la acosadora, se resta de restablecer el derecho en el lugar de trabajo y permanece inactivo. La omisión de actividad por este es la que resulta sancionada.

Entonces, hemos decidido concentrarnos en dos aspectos de este interesante fallo. En primer lugar, la manera como los tribunales entendieron la responsabilidad del empleador por los hechos cometidos por un

Profesor de Derecho del Trabajo y Seguridad Social, Doctor en Derecho Privado y Ciencias Criminales (2009), Université de París Ouest La Défense Nanterre. Actualmente Secretario Académico, Facultad de Ciencias Jurídicas y Sociales, Universidad Austral de Chile, Valdivia. Correo electrónico: pablo.arellano@uach.cl 
dependiente. En segundo término, una crítica el monto de la indemnización otorgada a las denunciantes.

\section{2) RESPONSABILIDAD POR ACOSO LABORAL POR OMISIÓN}

Los profesores Gamonal y Prado han definido al mobbing, o acoso laboral, como "un proceso conformado por un conjunto de acciones u omisiones, en el ámbito de las relaciones públicas y privadas, en virtud de las cuales uno o más sujetos acosadores crean un ambiente laboral hostil e intimidatorio respecto de uno o más acosados, afectando gravemente su dignidad personal y dañando la salud del o los afectados con miras a lograr distintos fines de tipo persecutorio" ${ }^{1}$. Estos autores además distinguen 3 tipos de mobbing considerando su origen, horizontal, vertical o mixto ${ }^{2}$.

En nuestro ordenamiento jurídico podemos encontrar la consagración del acoso laboral tanto en la Constitución como en el Código del Trabajo. En la Constitución en el artículo 19 número $1^{\circ}$.- El derecho a la vida y a la integridad física y psíquica de la persona. En el Código del Trabajo en el inciso segundo del artículo 2 al señalar que las relaciones laborales deberán siempre fundarse en un trato compatible con la dignidad de la persona. Además, luego de la ley $N^{\circ} 20.607$ de 8 de agosto de $2012^{3}$, se incorpora una definición de acoso laboral "entendiéndose por tal toda conducta que constituya agresión u hostigamiento reiterados, ejercida por el empleador o por uno o más trabajadores, en contra de otro u otros trabajadores, por cualquier medio, y que tenga como resultado para el o los afectados su menoscabo, maltrato o humillación, o bien que amenace o perjudique su situación laboral o sus oportunidades en el empleo". Ambas normas nos llevan a concluir que nuestro ordenamiento jurídico protege la integridad síquica del trabajador y que por tanto una situación de acoso o de ambiente hostil se debe proteger. Así, además, queda establecido al ser incluidas estas normas dentro del ámbito de aplicación del procedimiento de tutela de derechos fundamentales según el artículo 485 del Código del Trabajo. Este procedimiento puede ser impetrado en dos oportunidades durante la relación de trabajo y una vez concluida esta, cumpliendo con plazos y requisitos legales. Las denunciantes

Gamonal Contreras, Sergio y Prado López, Pamela, (2009) El mobbing o acoso moral laboral, LegalPublishing, 3ra Ed., p. 22.

Gamonal Contreras / Prado López, (2009) 23.

Sobre esta ley ver el Dictamen No 3.519/034, 3.519/034, de 9.08.12 9.08.12, fija sentido y alcance de las modificaciones introducidas por la ley No 20.607 al texto del inciso segundo del artículo $2^{\circ}$, del número 1 del artículo 160 y de los incisos segundo y sexto del artículo 171, todos del Código del Trabajo. 
de este fallo intentaron este procedimiento durante la vigencia de la relación de trabajo.

Resulta interesante destacar que tanto la doctrina como el legislador no contemplan la posibilidad de una sanción al empleador por inactividad u omisión de corregir las situaciones de acoso. Se habla de un proceso de hostigamiento, de un conjunto de actos, conducta de hostigamiento, etc. Pero no se incluye expresamente la posibilidad de omisión. Ante ello, presentamos dos posibles salidas. Por un lado, el texto de la ley 20.607 incluye el término "conducta" el cual puede ayudar a solucionar este problema. Debiendo entenderse a este término como acción u omisión, tal como se entiende en materia penal. Por otro, una omisión o pasividad del empleador puede ser sancionada por un no respeto del principio de protección que debe entregar el empleador a sus trabajadores. De ello derivaría que el empleador además de no desarrollar un acto de hostigamiento que constituya acoso laboral debe además proteger a sus trabajadores de todo acto que lo pueda constituir.

Según consta en el fallo en cuestión la jefa administrativa y cónyuge del empleador realizó actos constitutivos de acoso laboral los cuales dieron origen a enfermedades neuropsiquiátricas de las denunciantes. La trabajadora acosadora reconoce ser mañosa" y que posee un carácter fuerte. Pero más allá de lo anterior lo que llama la atención es la pasividad del empleador. En el considerando décimo remarca esta situación y asigna la responsabilidad al empleador señalando "que la conducta desplegada por doña Laura Vergara es imputable también al empleador Roberto Hadi, porque su pasividad como empleador permitió que estos acontecimientos se alargaran en el tiempo, sin poner coto al escenario descrito. La conducta de los empleados, sobre todo si se trata de su cónyuge, es siempre imputable al Conservador, quien como empleador delegó parte de sus facultades en ella y, por lo mismo, sus actos lo alcanzan".

Entonces, no se trataba de un trabajador cualquiera sino de uno unido por un vínculo familiar al empleador y que indudablemente no podía no saber lo que sucedía en el lugar de trabajo. En este sentido el considerando décimo del fallo señala claramente sobre la trabajadora en cuestión que "no es una mera administrativa como pretende hacerlo creer el denunciado, sino que su cónyuge, que tiene funciones de jefatura administrativa, con facultades de hecho incluso superiores al propio conservador, según se evidencia de los autos". Agrega el mismo considerando "que incluso en la mediación administrativa, el propio conservador ofreció como medida de solución que su cónyuge no continuare ejerciendo funciones en el establecimiento, para dar una solución a los problemas de convivencia”.

El fallo establece incluso como medida para encontrar una solución y mejorar el clima laboral en el considerando decimosegundo que la cónyuge del empleador "no continúe ejerciendo labores en dependencias del 
empleador, una vez terminada su licencia médica”. Si bien esta medida resulta de sentido común los tribunales de justicia no poseen facultades para indicarle a un empleador cuándo despedir a uno de sus trabajadores. Acertadamente la Corte de Apelaciones al resolver el recurso de nulidad presentado en esta causa confirma la sentencia de primera instancia pero deja sin efecto esta medida de separar de sus funciones al cónyuge del empleador ${ }^{4}$.

\section{3) ¿UNA CONDENA COMPENSATORIA DEL DAÑO SUFRIDO?}

El fallo objeto de este comentario propone una serie de medidas reparativas de los daños causados así como también fija un monto indemnizatorio por daño moral a cada una de las afectadas. Comentaremos brevemente cada una de estas medidas.

La sentencia de primera instancia fija como medidas reparatorias las siguientes:

A.- Que doña Laura Vergara Meerhson no continúe ejerciendo labores en dependencias del empleador, una vez terminada su licencia médica.

Como ya señalamos esta medida fue revertida por la Corte de Apelaciones de Temuco.

B.- Que el denunciado deberá, al reintegrarse las trabajadoras a sus labores habituales al término de sus licencias médicas, otorgar garantías mínimas de respeto a sus derechos fundamentales.

El fallo de segunda instancia no se refiere a este tema. Sin embargo, consideramos que no resulta necesario un pronunciamiento al respecto en razón que es obligación legal del empleador reincorporar a un trabajador luego que este haya hecho uso de una licencia médica.

C.- Que el empleador deberá realizar actividades de capacitación para el personal dependiente, en materia de buen clima laboral, las que podrán ser impartidas por la Inspección del Trabajo, o por profesionales idóneos, en un plazo que no exceda de dos meses.

Tal medida fue mantenida por la Corte de Apelaciones de Temuco y que encontramos acertada. Pero, se debería establecer condiciones mínimas para su ejecución, a saber que se obligue a participar a todos los trabajadores de la empresa. No sirve de mucho esta medida si tan solo un grupo reducido asiste a la capacitación.

Además, al acoger la demanda de tutela el tribunal de primera instancia condena al denunciado Roberto Hadi Bastias al pago de una indemnización por daño moral a cada una de las denunciantes los montos que se indican: Jaqueline Andrea Castillo Calderón: \$300.000; In-

4 Corte de Apelaciones de Temuco. 3 de julio de 2012, rol 105-2012. 
grid Paola Sepúlveda Cisterna: \$400.000; Ester Natali Villagra Castro: 400.000; Marcela Alejandra Quiñelen Cancino: \$500.000, y Ana Esperanza Moreno Vidal: 1.000.000. Estos montos fueron confirmados por el fallo se segunda instancia.

Respecto a este punto, nos quisiéramos detener un momento con respecto a la apreciación del daño moral. Entendemos que esto es una facultad propia del magistrado a cargo de la causa. Sin embargo, habiéndose probado los reiterados maltratos, hechos agravados por el vínculo que une a la acosadora y al empleador, y un reconocimiento de un carácter fuerte, resulta a nuestro parecer un poco exiguo el monto para compensar el daño sufrido ante enfermedades neuropsiquiátricas acreditadas. Entonces, cabe preguntarnos cómo poder evaluar y cuantificar el acoso laboral y sobre todo las agravantes que se pueden dar, como, por ejemplo, en este caso la omisión del empleador. Resulta además necesario preguntarse si se encuentra lo suficientemente comprendida la gravedad del acoso laboral. Una cuantificación débil nos lleva a pensar que la gravedad de los hechos se compensa en forma ligera. A nuestro parecer el trabajo como derecho humano, constituye una actividad vital para el hombre y su realización acorde a su dignidad es indispensable y debe ser valorado en consecuencia. No debemos olvidar el carácter alimentario que se la ha otorgado a las remuneraciones. El producto del trabajo sirve para que el trabajador y su familia puedan sobrevivir. Entonces, si el trabajo es tan importante para el hombre por qué no se le protege en forma consecuente. Se debe proteger al trabajador el contratarse y al momento del despido, pero sobre todo durante la relación de trabajo. Situaciones como la de esta caso produce una incertidumbre en el trabajador sobre su situación contractual cuyo menoscabo es protegido por el la figura del acoso laboral. La mantención de una relación laboral estable y digna debe ser protegida correctamente, y si es vulnerada, debe ser compensada dicha perturbación tomando en cuenta el valor del trabajo dentro de la sociedad.

\section{4) CONCLusiones}

El fallo en comento muestra de toda claridad lo tarde que llega la ley $\mathrm{N}^{\circ} 20.607$ sobre acoso laboral. Esto ya que los hechos de esta causa se producen y sancionan con anterioridad a esta regulación. La jurisprudencia ha logrado poder sancionar el acoso laboral sin una ley de la materia. La vigencia de un texto regulatorio hoy en día viene solo a reforzar el carácter exegético de nuestra cultura jurídica y dotar a jueces reacios a sancionar el acoso de un texto en el que se deben basar.

El caso de autos además nos presenta una situación particular con un acertado fallo. El empleador debe tener una actitud pro activa en el resguardo de los derechos de sus trabajadores y su pasividad debe ser san- 
cionada. El fallo nos muestra claramente la responsabilidad por omisión del empleador. Sin embargo, y como ya lo seńalamos, consideramos que la compensación del daño moral parece ser exigua ante la gravedad de los derechos afectados. 